\title{
An Analysis on Translation Errors in Online Vietnamese-English Menus
}

\author{
Nguyen Thi Nhu Ngoc ${ }^{1, *}$, Nguyen Le Minh Phương ${ }^{1}$, Le Anh Khoa ${ }^{1}$, Pham \\ Dang Khoa ${ }^{1}$, Tran Thanh Thanh Lam ${ }^{1}$ \\ ${ }^{1}$ Faculty of English Linguistics and Literature, University of Social Sciences \& Humanities, Vietnam National \\ University Ho Chi Minh City, Vietnam \\ *Corresponding author. E-mail: nhungoc@hcmussh.edu.vn
}

\begin{abstract}
With the development of tourism in Vietnam as one of the world's top destinations in recent years, food providers prefer to use bilingual menus, especially Vietnamese-English ones, as a useful tool for foreign customers to gain a better understanding of the national cuisine. However, there exist translation errors, which have caused several negative impacts on the customers. Therefore, identifying the translation errors and causes is quite helpful in promoting Vietnam's tourism, considering the status quo of the country's ongoing cultural integration within the context of the corona-virus pandemic. This paper collected the food names in online Vietnamese-English menus from 100 restaurants and foodservice establishments on Foody, one of the most original and well-received food review apps in Vietnam, and analyzed the collected data using both qualitative and quantitative research methods. The results indicated that there were four major translation error categories related to syntax, semantics, pragmatics, and translation-specific errors with 14 different specific error types based on a hybrid error-analysis model adapted from those popular in translation and currently used in the world. The results also revealed possible causes for these errors from different levels, including linguistic inaccuracy, amateurism, and irresponsibility. The findings may be used as a reference for translation training in Vietnam.
\end{abstract}

\section{Keywords: food, bilingual menu, translation error, Vietnamese-English translation, tourism}

\section{INTRODUCTION}

At the 2020 World Travel Awards (Russia), Vietnam was proudly the winner of the title Asia's Leading Culinary Destination 2020. Indeed, Vietnam has been on the way to becoming one of the world's top destinations, not only owing to its endless natural beauty and hospitable people but also its diverse, rich, and unique cuisine [1]. English is used as a primary means of communication for foreign visitors to Vietnam, so there is a trending norm of VietnameseEnglish menus in many food services, especially restaurants and food stores in big cities like Hanoi, Da Nang, and Ho Chi Minh. However, many food providers have still been facing difficulties dealing with transferring Vietnamese food names into English, which poses a significant problem for the translation a favorite online platform owning a database that quality and also influences the overall impression of Vietnamese cuisine, an important part of Vietnamese culture.

As a messenger among different languages and cultures, translation is a critical component of intercultural communication. There is no global communication without translation [2]. Thus, it may be disastrous if human beings are unable to communicate well with each other due to poor translation quality. People around the world, especially international tourists, have preferred to browse favorite or new dishes on the Internet - convenient as a source of reference of the digital era, and even more so during the worldwide Covid-19 pandemic. This paper raises an issue about translation errors and their causes in online Vietnamese-English menus on Foody,

allows multi-user inputs concerning food vendors in 
Ho Chi Minh City, Vietnam. The research is conducted to answer the question, "What are common translation errors and possible causes in online VietnameseEnglish menus on Foody?" We hypothesize that the data analysis points out errors existing in VietnameseEnglish menu translations; and that there are some certain factors related to cultural and linguistic differences as well as translators' unprofessional skills leading to such errors.

The paper is expected to be of considerable use for those who are interested in the translation of food names. Then the research results may help and improve the translation quality of the bilingual menus currently used on Foody in particular and serve as a useful reference source for translation training and practice at the tertiary level.

\section{LITERATURE REVIEW}

\subsection{Menus and their translation}

A menu is "a detailed list of the foods served at a meal, or the foods served" [3]. For some food experts, a menu is "a written list whose function is to inform the customers what dishes are available in a restaurant" [4]. In this research, the term "menu" refers to an online list of the dishes served at a restaurant or food vendor, and its target reader is the customers, including any foreigners who come to or intended to come to
Vietnam, have different backgrounds, and use English as a means for communication.

The menu is described as a text with a double function: an informative text that tells the customers what they need to know about the dishes available; and it is a means of advertising aimed at expressing the restaurant's image and the culture of the country [5]. Thus, it can be seen that menus share the features of advertisements. Its language should involve the use of a simple, informal, personal, friendly, and easy-to-read style, in addition to the use of descriptive adjectives, verbs, adverbs, and nouns to highlight and exaggerate a situation [6].

The application of bilingualism can lead to greater efficiency in the culinary environment [7]. For example, the impact of the use of English in printed and electronic advertisements in Taiwan and recognizes that English is used because it creates positive impressions; and English has been associated with globalization, good quality, middle-class lifestyle, urban experience, and modernity of the younger generation [8]. Accordingly, we can see those bilingual menus are quite essential in this globalized world because they help tourists around the world to have a good choice of what to enjoy in a visited country and they help to promote the cuisine of a country to the world as in Figure 1.

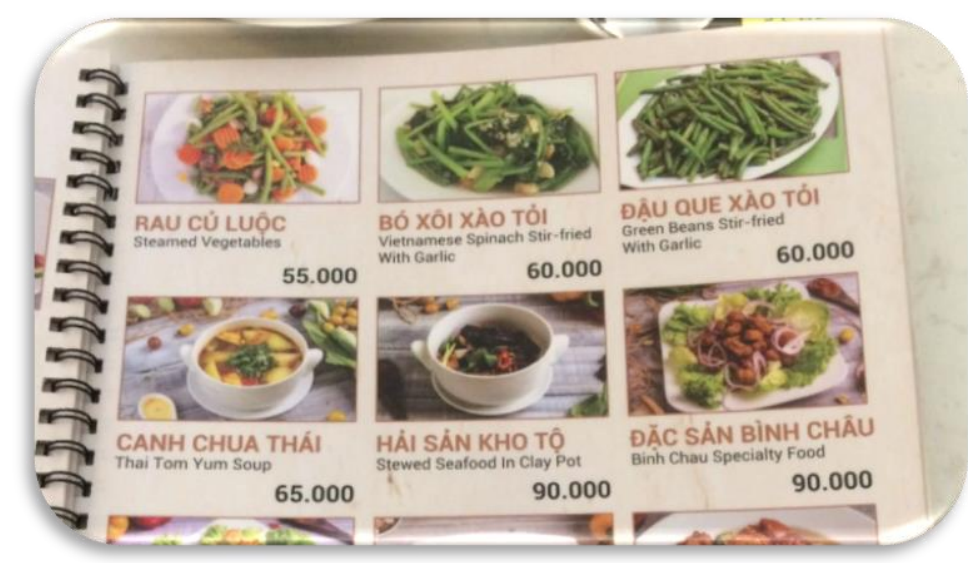

Figure 1. Menu of the Loving Vegan Kitchen, located at 39A Co Bac, District 1, HCMC

To successfully work as a communication tool, words should be selected carefully for fascinating and unforgettable impressions of menus. A well-designed menu is a good map that guides its customers while also being able to live up to their expectations. In respect to language, a good menu should include easy and straightforward language, precise, accurate description such as nutritional information, food preparation, and cooking method, and so on [9]. To produce good bilingual menus, a translation should fulfill its purpose, i.e., it is a communication tool between the food providers and foreign customers and facilitates processes in tourism and consumerism in general [10].

As Chiaro \& Rossato [11] recommends, the process of 
translation from a language to another one with presumably and vastly different cultural characteristics requires much care and effort, which is similar to the process of preparing a dish. Not only do the two processes both crave the "ingredients" in order to produce the "dish," but the essential steps to creating an appealing dish or translation in both processes are also alike. To prepare a stunning dish for diners, the cook has to examine the original recipe, find out the right ingredients and consider the appropriate cooking methods. Similarly, in translation, upon looking into the original recipe or text, the translator must be able to identify the right words, then contemplate strategies to provide the readers with an accurate and appropriate translation. However, in order to serve easily digestible dishes or easily comprehensive translations, both the cook and the translator may involve the changes such as the omission or substitution of an ingredient or an expression in their strategies. This situation can also result in lingua-cultural mistranslations. This argument deeply visualizes the translation process and production of bilingual menus.

However, in many people's minds, any bilingual person can be a translator. The low entry standards in Vietnam have produced unqualified translators and incorrect translation products. Moreover, many people do not consider that translation is an intricate practice, so they often expect the translator to provide a good translation in a short period of time for low pay. In addition, due to the increasing need for bilingual menus, more and more translation and localization companies begin to appear, bringing about price competition, yet not necessarily higher quality, leading to a lack of standardization and regulation. These problems have been found for years because the public do not correctly understand the translation profession [12]

\subsection{Translation errors and model of translation error categories}

Séguinot [13] defines a translation error as "an offense" that is against (a) the function of the translation, (b) the coherence of the text, (c) the text type or text form, (d) linguistic conventions, (e) culture- and situation-specific conventions and conditions, and (f) the language system. Pym [14] identifies errors in translation as a manifestation of a defect in any factors entering the skills in translation, then categorizes them into two types: binary translation errors - complete incorrectness of translation; and non-binary translation errors - those not totally wrong and able to be improved. In contrast, Hatim \& Mason [15] describe translation errors as (1) significant (unmotivated) mismatches of denotational meaning between source and target text (subdivided into omissions, additions, and substitutions), and (2) breaches of the target-language system (e.g., orthography, grammar).

Séguinot's definition is quite fit for errors in translating Vietnamese food names with culture- and situation-specific conventions and conditions that may not exist in the Western culture; Pym's view is right in case of translators' bad skills causing incorrect translations, and Hatim \& Mason's depiction provides more details about errors related to linguistic factors and bad translation techniques. Although each of them looks at translation errors from a different angle, they all mean that translation errors violate the meanings, structures leading to misunderstandings, incomplete or even wrong messages. In addition, Pym [14] emphasizes there are various causes of translation errors such as lack of comprehension, inappropriateness to readership, and misuse of time, and they involve different levels as language, pragmatics, and culture. From their viewpoints, we can discover the causes of such errors.

Dastjerdi and Abdolmaleki [16] combine the error list by the American Translators Association [17] with 22 types of errors (version 2010) and Keshavarzs' the linguistic taxonomy of errors [18] with three categories, namely grammatical errors, semantic errors, and pragmatic errors into a hybrid model of translation error categorization in which they group translation errors into 4 major categories, including syntactic errors, semantic errors, pragmatic errors, and translation-specific errors. In our view, among various error lists constructed by translation companies or associations in the world, the American Translators Association's one is more appropriate in our case because it refers to both cultural and linguistic errors in detail and then highly meets the communication purpose in menu translation. Therefore, the application of Dastjerdi and Abdolmaleki's hybrid model of translation error categorization would be quite appropriate for our research. Besides, this hybrid model of error categories is more convenient for our research under both the academic and communicative perspectives. However, we have made a few adjustments for better convenience in the new research context with 16 types of errors instead of 20, as in Dastjerdi and Abdolmaleki's, as shown in Table 1. 
Two errors, illegible handwriting and indecision in word choice in the ATA's 22 error list (version 2010) are not presented in the model, and this is acceptable for our research because all online menus are clearly typed, and there are no blanks in their English translation. Besides, in our adapted model, the ATA error list version 2017 is applied. Then some error types are considered as sub-category errors. For example, the syntax error and the word form error are included as sub-category errors in the grammar. Also, style and register are recognized as two sub-category errors of text type. On the other hand, addition and omission are now separated into two types instead of a single one. Besides, all Vietnamese food names are nouns or noun phrases, so no errors related to punctuation and incomplete passage are found, so we removed them in the adapted model.

Table 1. The Hybrid Model of Error Categorization

\begin{tabular}{|c|c|c|}
\hline Error categories & $\begin{array}{l}\text { Dastjerdi and Abdolmaleki's Hybrid } \\
\text { Model of Error categorization (2012) }\end{array}$ & $\begin{array}{l}\text { Our model adapted from that of } \\
\text { Dastjerdi and Abdolmaleki (2012) }\end{array}$ \\
\hline Syntactic Errors & $\begin{array}{l}\text { 1. Grammar } \\
\text { 2. Syntax } \\
\text { 3. Punctuation } \\
\text { 4. Usage } \\
\end{array}$ & $\begin{array}{l}\text { 1. Grammar } \\
\text { 2. Usage }\end{array}$ \\
\hline Semantic Errors & $\begin{array}{l}\text { 1. Addition or omission } \\
\text { 2. Terminology, word choice } \\
\text { 3. Too freely translated } \\
\text { 4. Too literal, word-for-word } \\
\text { translation } \\
\text { 5. False cognate } \\
\text { 6. Ambiguity } \\
\text { 7. Accents and other diacritical marks } \\
\text { 8. Case (upper case/lower case) } \\
\text { 9. Word form } \\
\text { 10. Spelling }\end{array}$ & $\begin{array}{l}\text { 1. Addition } \\
\text { 2. Omission } \\
\text { 3. Terminology, word choice } \\
\text { 4. Too freely translated } \\
\text { 5. Too literal, word for word translation } \\
\text { 6. False cognate } \\
\text { 7. Ambiguity } \\
\text { 8. Spelling }\end{array}$ \\
\hline Pragmatic Errors & $\begin{array}{l}\text { 1. Misunderstanding of the original } \\
\text { text } \\
\text { 2. Mistranslation into a target language } \\
\text { 3. Register } \\
\text { 4. Style }\end{array}$ & $\begin{array}{l}\text { 1. Misunderstanding of the original text } \\
\text { 2. Mistranslation into a target language } \\
\text { 3. Text type }\end{array}$ \\
\hline $\begin{array}{l}\text { Translation- } \\
\text { specific Errors }\end{array}$ & $\begin{array}{l}\text { 1. Incomplete passage } \\
\text { 2. Inconsistency }\end{array}$ & 1. Inconsistency \\
\hline
\end{tabular}

\subsection{Previous studies}

There have been noticeable researches worldwide regarding translating menus into English from a number of languages, such as menu translation from Mandarin into English [19]; influences of improper menu translation from Thai into English [20]; translation errors in three restaurants in Yogyakarta city, Indonesia and the "acceptability" level of these translation errors to customers [21]; common techniques in translating menus from Persian into English [22]; approaches and theoretical foundations in translating menus into English [23] and so on.
However, there is not much in-depth research on the translation of food names from Vietnam into English. Some researches were conducted on other fields of translation, such as bilingual public signs in tourist [24]; and bilingual photo captions at a museum [25]. Thus, this research unveils another issue related to online bilingual menus, contributing more to sharpening the picture of translation quality from Vietnamese into English. 


\section{METHODS}

\subsection{Research context and sampling}

The unpredictable sequences of the Covid-19 pandemic have led to the temporary or even permanent closing of numerous food vendors with bilingual menus in Vietnam and, more specifically, Ho Chi Minh City. That is the reason why the researchers decided to collect online Vietnamese-English menus on an application, namely Foody.

The menu samples were found on Foody, an online platform owning a database that receives multi-user inputs concerning various information on food vendors and other services. This application supports users to search and review food locations in big provinces and cities in Vietnam, such as Ho Chi Minh City, Hanoi, Da Nang, Hai Phong, Nha Trang. Since its foundation in 2012, Foody has become one of the most successful start-ups in Vietnam.

For convenience sampling, one hundred bilingual menus of restaurants of all sizes as well as foodservice establishments in District 1, Ho Chi Minh City, Vietnam, were selected as the data source for research. This district serves as the metropolitan district of the city that attracts numerous visitors to Vietnam. It can be boastful that District 1 is a kingdom of Vietnamese cuisine for tourists to discover and enjoy as it has almost everything from traditional dishes to cuisines of countries all over the world, from fancy restaurants as well as mid-range eateries to street food stalls.

Besides, to find out reasoning arguments for causes of translation errors, this research inherited the achievements from previous studies and reliable reference sources about Vietnamese culinary arts, especially food forums and popular cookbooks, and searched for useful and reliable evidence from them to find out good tentative translations after the analysis of possible causes of errors in the collected data.

\subsection{Research design}

This is mixed-method research where the data were collected from archival documents using both quantitative (statistical and classification) and qualitative (library method) approaches. Both approaches were employed to identify the translation errors which come from a variety of reasons and also to construe possible causes of these errors. In addition, the contrastive and descriptive methods were employed so that the original texts and their translations were contrasted; thereby errors in menu translations could be identified and grouped in appropriate categories as mentioned in Section 2.

\subsection{Data collection and analysis procedure}

One hundred Vietnamese-English menus were all collected from the application Foody in early 2021 in the form of visual samples, i.e., photos and screenshots. Menus were photographed, scanned, enhanced (until proper visibility is achieved), and aggregated into menu sets according to the streets in District 1, Ho Chi Minh City.

Then the menu contents were transcribed into text form for processing and analysis. To assess the accuracy of these bilingual menus, the research group was divided into two pairs; and each pair analyzed the one hundred bilingual Vietnamese-English menus for error identification and categorization based on the model adapted from Dastjerdi \& Abdolmaleki's [16] hybrid model in Table 1. After the two pairs compared their findings, should there be any differences in our findings, the two pairs would discuss to reach an agreement. In the event of disputes, we would then seek consultancy from a third party being a full-time professional translator who is currently an employee at a translation company in Ho Chi Minh City and has some experience in Vietnamese cuisine translation.

Each of the errors in one menu was subsequently digitalized and compiled into the database for processing. Thus, common errors found in most of the menus were explored through the analysis, from which some possible causes were found and demonstrated. This procedure is arguably appropriate as it works with the authentic data collected from the research samples so that the research question would be effectively resolved.

\section{FINDINGS AND DISCUSSION}

\subsection{Common errors in online Vietnamese- English bilingual menus on the application Foody}

After analyzing the translations of 100 bilingual menus, we found 3,718 turns of translation errors. All were made and correlated to the formatting of the original texts. The numbers of translation errors and their frequencies are presented statistically in Table 2. 
Table 2. Common translation errors in Vietnamese-English menus

\begin{tabular}{|c|c|c|c|}
\hline Error categories & Sub-categories & Count & Percentage $(\%)$ \\
\hline \multirow[b]{2}{*}{ Syntactic errors } & Grammar & 224 & 6 \\
\hline & Usage & 140 & 3.8 \\
\hline \multirow{8}{*}{ Semantic errors } & Addition & 201 & 5.4 \\
\hline & Omission & 574 & 15.4 \\
\hline & Terminology, word choice & 590 & 15.9 \\
\hline & Too freely translated & 196 & 5.3 \\
\hline & Too literal, word for word translation & 94 & 5.2 \\
\hline & False cognate & 264 & 1.7 \\
\hline & Ambiguity & 120 & 3.2 \\
\hline & Spelling & 306 & 8.2 \\
\hline \multirow[t]{3}{*}{ Pragmatic errors } & Misunderstanding of the original text & 147 & 4 \\
\hline & Mistranslation into the target language & 554 & 14.9 \\
\hline & Text type & 206 & 5.5 \\
\hline $\begin{array}{l}\text { Translation- } \\
\text { specific errors }\end{array}$ & Inconsistency & 102 & 2.7 \\
\hline \multicolumn{2}{|r|}{ Total } & 3,718 & 100 \\
\hline
\end{tabular}

Of the four categories, the semantic errors were the most with 57.4\%; pragmatics errors came the second with $24.7 \%$; the third was syntactic errors with $9.8 \%$, and translation-specific errors made up the least with only $2.7 \%$. These figures truly reflect challenges that translators may face when dealing with the denotative and connotative meanings as well as cultural values rooted in Vietnamese food names, which results in the larger numbers of semantics and pragmatic errors. Whereas, as we mentioned above, the food names are all nouns and noun phrases, so there were not many syntactic errors. Similarly, the translation-specific errors related to inconsistency were sparse and mainly those related to no cohesion in the translation of the same menu. As for the sub-types, the most common errors were those about terminology and word choice (15.9\%), omission $(15.4 \%)$, mistranslation into the target language (14.9\%), and spelling (8.2\%).

\subsection{In-depth discussions about some typical examples of the translation errors and their causes in online Vietnamese-English menus}

Below are some examples of the four categories of translation errors found in the collected data. An indepth analysis and discussion for each would be helpful to identify possible causes and useful to improve the translation quality.

\subsubsection{Syntactic errors}

Syntactic errors are about the wrong use of structures and improper modification, causing meaningless translations or misunderstandings. Many of them are non-binary errors and cannot be rearranged in any way to make the food names in English meaningful or understandable.

Table 3. Some common syntactic errors in Vietnamese-English menus

\begin{tabular}{|l|l|l|l|}
\hline Sample & Source text & Wrong translation & Suggested translation \\
\hline Grammar & gỏi rau muống & glory morning salad & morning glory salad \\
\hline Usage & bánh mì thịt & bread meatloaf & loaf of bread with meat \\
\hline
\end{tabular}


In these examples, the bad syntactic choice, unnatural word order, and no use of prepositions make the translations incomprehensible and cause real confusion for food users.

\subsubsection{Semantic errors}

Semantic errors are those that may impact the understanding of customers about specific features of food items on a menu. Translations with such errors may be unidiomatic, unclear, less informative, meaningless, or confusing. Some semantic errors are presented in Table 4.

Table 4. Some semantic errors in Vietnamese-English menus

\begin{tabular}{|c|c|c|c|}
\hline Error & Source text & Wrong translation & Suggested translation \\
\hline Addition & cá lóc chiên xù & $\begin{array}{l}\text { grilled mud-fish - steamed/ } \\
\text { deep-fried }\end{array}$ & deep-fried mud-fish \\
\hline Omission & lẩu đầu cá hồi măng chua & salmon head hot pot & $\begin{array}{l}\text { hot pot with salmon head and sour } \\
\underline{\text { bamboo shoots }}\end{array}$ \\
\hline Terminology & cá bớp áp chảo & pan-fried tuna & sautéed cobia \\
\hline $\begin{array}{l}\text { Free } \\
\text { translation }\end{array}$ & cá chẽm áp chảo & $\begin{array}{l}\text { fresh sea bass cooked to } \\
\text { perfection }\end{array}$ & pan-fried sea bass \\
\hline $\begin{array}{l}\text { Literal } \\
\text { translation }\end{array}$ & đậu hủ đội nón & dressing top tofu & tofu topped with garnishes \\
\hline $\begin{array}{l}\text { False } \\
\text { cognate }\end{array}$ & thiên lý xào bò & nature of fried beef & $\begin{array}{l}\text { stir-fried beef with Tonkin Jasmine } \\
\text { flowers }\end{array}$ \\
\hline Spelling & đùi gà & chicken thighs & chicken thighs \\
\hline
\end{tabular}

The first example has some more explanation "steamed/ deep-fried" that seems to be informative but leads to a bad stylistic effect; as a result, we have an additional error due to relevant information but unnecessary for a proper translation. In contrast, the second one does not give enough ingredients of the food, i.e., sour bamboo shoots - an essential part that makes a special flavor of the food and also serves as a decisive factor for the choice of customers. Thus, the omission error in this example is incompetent and may reduce the clarity of the menu. The target readers will likely not realize the deletion of this information from the source text. However, the lack of information, thus lack of clarity from the translated text, combined with another syntactic error, makes the translation less acceptable.
In the third example, "cá bớp" should be "cobia" rather than "tuna" because they are two different kinds of fish, and also the cooking methods "sauteing" and "panfrying" are dissimilar - the first using a relatively small amount of oil/ fat and the second taking place at lower heat.

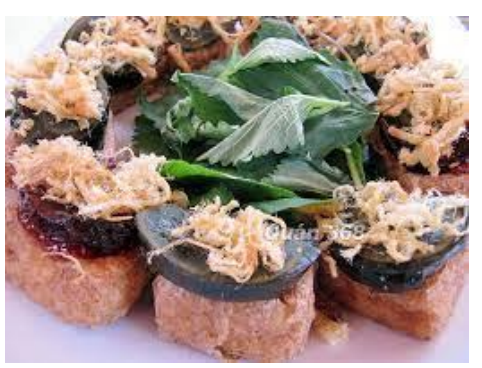

Figure 2. Đậu hủ đội nón

In sample 4, the food is named metaphorically based on its decoration, as in Figure 2. The word "đội nón" in Vietnamese literally means "to wear a hat" or to "top with something." Hence, the word choice in this literal translation in English would have been correct if it 
were to be applied in other non-culinary contexts. Therefore, we suggest "top with garnishes" instead, which not only respects the metaphorical meaning but also suits the culinary expression.

The next instance shows the translator transferred the food name from Vietnamese to English as the way he/she might feel so excited and creative with the phrase "cooked to perfection,"; and this creation somehow alters the meaning of the source text, causing a free translation error.

Similarly, the sixth case is really a flawed translation with a false cognate error. Actually, "thiên lý" is the name of a flower used as a kind of vegetable in Vietnam, and its homonyms (same sound and same spelling) in Sino-Vietnamese refers to "thousand miles," "natural reason," or even "the high sky." It was then translated into "nature" because the translator might misunderstand its denotative meaning in context

Table 5. Some pragmatic errors in Vietnamese-English menus on Foody

\begin{tabular}{|l|l|l|l|}
\hline Error & Source text & Wrong translation & Suggested translation \\
\hline $\begin{array}{l}\text { Misunderstanding of } \\
\text { the original text }\end{array}$ & cải Chua & sour cabbage & pickled mustard greens \\
\hline $\begin{array}{l}\text { Mistranslation into the } \\
\text { target language }\end{array}$ & cánh gà Cao nguyên & tropical chicken wings & $\begin{array}{l}\text { chicken wings grilled with } \\
\text { Vietnam's Central Highlands style }\end{array}$ \\
\hline Text type & cơm sườn non & $\begin{array}{l}\text { cooked rice with grilled } \\
\text { immature rib }\end{array}$ & rice with small grilled pork ribs \\
\hline
\end{tabular}

In the first sample, the translator might misunderstand two terminologies, "cải" (mustard greens) and "bắp cải" (cabbage) in Vietnamese. As we can see in Figure 3 below, the first terminology refers to the main ingredient in the food "cải chua," a traditional and considered "thiên" as a shortened form of "thiên nhiên" (nature), or even use a machine translation without revision. At the same time, he/she literally translated individual words in the source text and produced confusion in the target text.

The final specimen illustrates translations with incorrectly spelled words. The spelling error "chicken" here is possibly due to typo or oversight upon reviewing the translation.

\subsubsection{Pragmatic errors}

Pragmatic errors are those that may put customers in a very dilemma that they likely do not realize they are getting the wrong information about food items listed in menus. Table 5 presents some pragmatic errors that may prevent customers from knowing or trying traditional specialties in Vietnam.

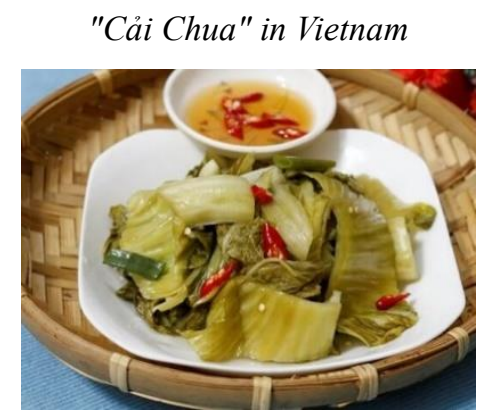

"Sour cabbage," a common addition in meals found in Asian countries

Figure 3. Misunderstanding of the original text 
In the second instance, the Vietnamese food has been completely changed into another one due to the mistranslation of the cooking method. In English, "tropical" refers to the use of tropical-fruit ingredients such as mango, pineapple, or orange juice, while "Cao nguyên" is related to a local cooking style of the minority people in Vietnam's Central Highlands.

The text type error occurs in the third example due to the register expressed in the noun phrase "immature rib" as an English equivalent of "sườn non" is rather formal or sounds "a biological term" for a folk dish that is very popular in street shops as well as restaurants in Vietnam.

\subsubsection{Translation-specific errors}

The translation-specific errors in online bilingual menus we found in this research are inconsistent ones. They refer to the translators using more than one equivalent for a certain cooking method or ingredient presented in the same menu. An interesting example is the menu of Mam Bac Restaurant, located at 94 Ho Tung Mau, District 1, Ho Chi Minh City, in Figure 4. There are various English equivalents for the Vietnamese phrase "kho tiêu" (in which "kho" refers to a cooking method, and "tiêu" a kind of spices commonly used in Vietnamese family meals, including: "kho tiêu" = "slow cook... with pepper", "with pepper" (cooking method being omitted), "cooked with sauce and pepper."

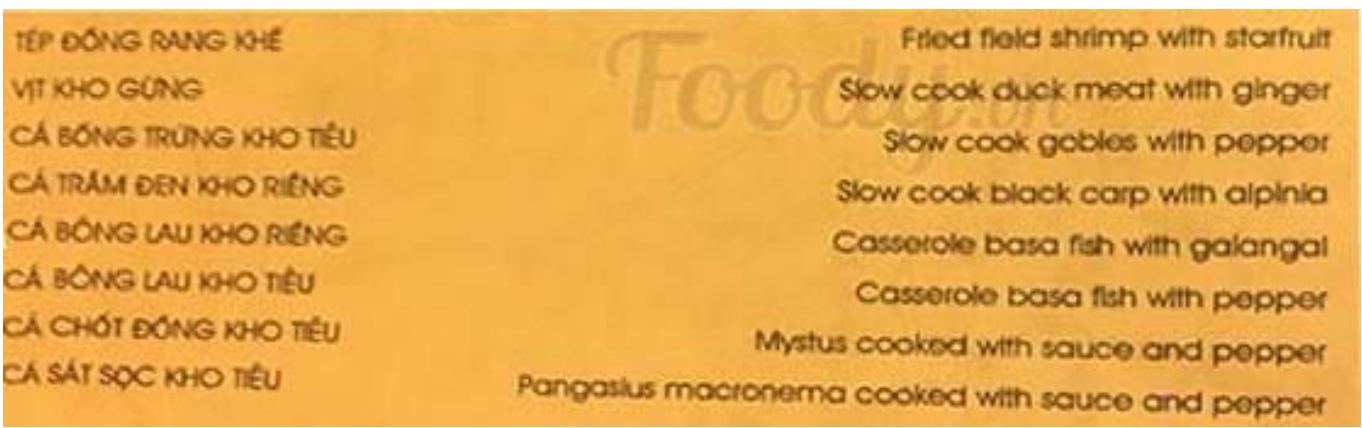

Figure 4. Menu of Mam Bac Restaurant on Foody

\section{CONCLUSION}

\subsection{Summary of the major findings and implications}

Online Vietnamese-English menu translation problems certainly affect intercultural communication for foreign customers in Vietnam due to 14 types of errors in the four categories, namely syntactic, semantic, pragmatic, and translation-specific errors as analyzed and discussed above. They all lead to confusion and misunderstanding. We can come to a summary of the main findings and relevant implications as follows:

(1) Half of the errors belong to the category of semantic errors, and pragmatics errors also make up a considerate part. However, small amounts of syntactic errors and translation-specific errors (just inconsistency) are found in online bilingual menu translation. The findings in this research reveal that improper use of terminology, omission, and mistranslation are three major error types; and their discussions considerably match with what has been affirmed in some researches: the context of the menu would affect the translation quality (Wei-xiong, 2007); much confusion is found in translated names (Duangsaeng and Chanyoo, 2017); and when the most errors are terminologies and omissions, they may lead to an unacceptability level rather than the "acceptability" level of these translation errors to customers (Tanudirjo, 2020). Therefore, translation majors at the tertiary level should be seriously warned about translation errors they may commit not only in the field of gastronomy but also in others. Besides, the findings in this research can serve as an authentic reference source for teachers to design practice activities about error identification and revision in their translation courses, which subsequently helps students to improve their translation assessment as well as familiarize themselves with professional translation. 
(2) Many translation errors in the online bilingual menus are committed because translators may try to provide some explanation or description of food items that do not actually have one-to-one equivalents in English, and even when they get one that is similar to some extent, it does not mean that this equivalent is sufficient to explain a Vietnamese dish. Moreover, menu translation has been considered a tough task because there are no fixed standards for translating food names, as it has cultural and emotional associations and meanings as well; and it is not easy to come up with a concise description of a food item in the space available on a menu sheet. Therefore, translators should spend more time and effort on worthwhile translations.

(3) Some translations are unnatural and unidiomatic, even ignoring metaphorical meanings that food providers desire to express through their food names. The researchers themselves sometimes have thought that many translations were products of machine translation or amateur translators without any revision. Maybe, due to the increasing need for bilingual menus, more and more translation and localization companies begin to appear, bringing about price competition, yet not necessarily higher quality, leading to a lack of standardization and regulation (Huang \& Huang 2008). It is a fact that translation agencies are paying low fees, which has become an ethical issue worldwide; and that many companies, especially small companies, do not value the quality of translation or appreciate how mistranslation can affect their international business; therefore, they are not willing to pay for a professional translator at the regular rate. Instead, they will try to either translate by themselves or hire someone who will translate cheaply, regardless of the quality [26] It also means that in most of the cases in this study, menus have been translated by those who are not professional or devoted translators and therefore, not familiar with culinary terms. This compounds the issue and can be particularly difficult for restaurants to change their menu offerings daily. Thus, more policies on translation payments should be established for better translation qualification.

\subsection{Limitations and recommendations}

One limitation the researchers encountered was that the number of menus samples examined was obviously limited, and the evaluation was confined to Vietnamese-English translation, despite the inclusion of other languages (e.g., Chinese, Japanese) in several menus on Foody. Another limitation is that while conducting context analysis, some of the error classifications were identified to be somewhat similar in nature, especially when put into perspective with their real-world representations. One notable example is the comparison between inappropriate terminology and inappropriate semantic translation. Several items in the samples caused considerable debate in choosing the rational category. Finally, some compromise was made to some extent.

As a result, this research may offer opportunities for future research in more categories of translation errors and difficulties as well as solutions in other disciplines in tourism besides gastronomy. A comparison may be carried out concerning how English-Vietnamese translation problems differ from those of other language pairs because there would be some variations largely depending on the language and cultural similarities and differences.

After evaluating a substantial number of samples in the online menus collected on Foody, we found the need for proper education and quality control in menu translation even greater than when we set out to conduct our research. The subpar quality of many of these menus is a significant hindrance in creating an image that represents Vietnamese cuisine in all its uniqueness and authenticity. Therefore, it is not only a pressing matter in the linguistic space but also in the cultural embodiment of the country. Some sets of criteria for menu translation should be examined and established. Besides, the possibilities of expanding the field of menu translation are just as diverse as any other field of translation since restaurants and food vendors will always desire to address a wider audience than that of their language. This is especially true with those in countries whose primary language is not an internationally (or widely) used one.

All in all, the research results have successfully answered the research question and provided strong support for our hypothesis. This research was worth conducting because it aims at raising awareness towards the role of accurate translation in restaurants and other small business models, as well as contributing to the ESL field and students who are learning translation. The fact that this study covers a wide variety of samples (different cuisines, vegetarian 
dishes, etc.) will be of use to translators of all levels who are working in the field of food names. For those who love studying or cultivate an interest in Vietnamese to English translation of food names, this study is a good starting point. For professional translators, it may serve as a valuable referential source for use in many situations apart from menu translation, such as intercultural communication and interpreting.

\section{AUTHORS' CONTRIBUTION}

Dr. Nguyen Thi Nhu Ngoc is currently Vice-dean and Chair of the Department of Translation and Interpreting at the Faculty of English Linguistics \& Literature (EF), University of Social Sciences \& Humanities (USSH), Vietnam National University Ho Chi Minh City (VNUHCM). Her research group includes four senior English majors, Nguyen Le Minh Phương, Le Anh Khoa, Pham Dang Khoa, and Tran Thanh Lam, who are highly inquisitive students with great love for translation research and desire to contribute to the translation quality in Vietnam with a contemporary sensibility and critical mindset. The paper is a fruit of the teacher-student cooperation in the early quarter of the year 2021 in the Covid-19. The contribution of each author is as follow:

Nguyen Le Minh Phuong and Pham Dang Khoa collected data ad wrote the first draft of the paper.

Le Anh Khoa and Tran Thanh Thanh Lam collected the data and wrote the Research Methodology and References.

Nguyen Thi Nhu Ngoc gave instructions for data collection, rewrote some major parts, and revised the paper.

\section{ACKNOWLEDGMENTS}

This paper is a product of a student research project at the university level (based on Announcement No. 749/TB-XHNV-ĐN\&QLKH by the USSH, VNUHCM). In April 2021, the project was approved by the EF, USSH, VNUHCM, which encouraged the research group to write this paper. We would like to express our great thanks to those who have supported us to complete the project and the paper.

\section{REFERENCES}

[1] N. Quy, "Vietnam named among world's fastestgrowing travel destinations," [Online]. Available: https:/e.vnexpress.net/news/travel/places/vietna m-named-among-world-s-fastest-growing-travel- destinations-3980649.html.

[2] P. Newmark, "Chapter 3. No Global Communication Without Translation," in Translation Today: Trends and Perspectives, G. Anderman and M. Rogers, Bristol, Blue Ridge Summit: Multilingual Matters, 2003, pp. 55-67.

[3] Merriam-Webster, "Menu." Accessed Dec. 24, 2020 [Online]. Available: https://www.merriamwebster.com/dictionary/menu.

[4] B. Hardyanto, "A Translation Analysis of Dishes in The Book Menu of Omah Sinten Restaurant," Ph.D. Dissertation, Dept. of English, Sebelas Maret University, Indonesia, 2016. Available: https://core.ac.uk/download/pdf/33485951.pdf.

[5] J. Ruzaite, "Text Typology in Translation: A case study of menu translations," Darbai in Dienos (Deeds and Days), vol. 45, pp. 257-271, 2006 [Online]. Available: https://hdl.handle.net/20.500.12259/32300

[6] W. D. Wallace, "How Registers Register: Toward the Analysis of Language Use," IRAL International Review of Applied Linguistics in Language Teaching, vol. 19, no.1-4, pp. 267-286, 1981.

[7] I. C. Ke, Y. H. Kuo, “The application of bilingual menus and vendors' perceptions in the night markets of university areas in Taiwan," Journal of Tourism and Travel Research, vol. 8, no. 2, pp. 37$58,2013$.

[8] J. L. Hsu, "Glocalization and English Mixing in Advertising in Taiwan: Its Discourse Domains, Linguistic Patterns, Cultural Constraints, Localized Creativity, and Socio-Psychological Effects," Journal of Creative Communications, vol. 3, no. 2, pp. 155-183, May 2008. DOI:10.1177/097325860800300203.

[9] B. Davis, A. Lockwood, P. Alcott, I.S. Pantelidis, "Food and Beverage Management," 6th ed. Routledge, 2018. https://doi.org/10.4324/9781315563374

[10] S. Li, "A corpus-based multimodal approach to the translation of restaurant menus, Perspectives," vol. 27, no.1, pp. 1-19, Jun. 2019. DOI: 10.1080/0907676X.2018.1483408.

[11]D. Chiaro and L. Rossato, "Food and translation, translation and food," The Translator, vol. 21, no. 3, pp. 237-243, Dec 2015 [Online]. Available: https://doi.org/10.1080/13556509.2015.1110934. 
[12] Y. Huang and Q. Huang, "The translation industry in China: Current development and potential for international cooperation," Translators Association of China (TAC), 2008. Available: http://www.tac-online.org.cn/en/tran/200910/13/content_3182787.htm.

[13] C. Séguinot, "Interpreting errors in translation," Meta, vol. 35, no.1, pp. 68-73, 1990 Available: https://doi.org/10.7202/004078ar.

[14]A. Pym, "Translation error analysis and the interface with language teaching," in The teaching of translation, C. Dollerup \& A. Loddegaard, Eds. Amsterdam: John., 1992, pp. 279-288. DOI: 10.1075/z.56.42pym.

[15]B. Hatim, I. Mason, "The Translator as Communicator," London: Routledge, 2005. [Online] Available: https://doi.org/10.4324/9780203992722.

[16] H.V. Dastjerdi and S.D. Abdolmaleki, A Study of Translation Problems of Tourism Industry Guidebooks: An Error Analysis Perspective, International Journal of Foreign Language Teaching and Research, Art.7, Vol.1, Issue 1, pp. 71-82, Mar 2013 [Online]. Available: http://jfl.iaun.ac.ir/article_550500.html.

[17] American Translators Association (ATA), "Explanation of Error Categories," Accessed Dec 24, $2020 \quad$ [Online]. Available: https://www.atanet.org/certification/how-theexam-is-graded/error-categories/.

[18] M.H. Keshavarz, Contrastive analysis, and error analysis. Tehran, Iran: Rahnama Press, 1994 [Online]. Available: https://in.bok.as/book/2470374/244892.

[19] W.U. Wei-Xiong, "Yes to Pragmatic Translation, No to Literal Expression - On C to E Menu Translation Originated from the Banquet in Honor of Her Majesty Elizabeth II," Shanghai Journal of Translators, Issue 4, 2007 [Online]. Available: China National Knowledge Infrastructure (CNKI).

[20] W. Duangsaeng, N. Chanyoo, Intelligibility of Thai English Restaurant Menus as Perceived by Thai and Non-Thai Speakers. Journal of Language Teaching and Research, Vol. 8, No. 6, pp. 1081-1089, Nov 2017. DOI:10.17507/j1tr.0806.08.

[21] K.R. Tanudirjo, "The English translation of food menu in three restaurants in Yogyakarta: the acceptability and the strategies," Ph.D. dissertation, Dept. of English Letters, Santa Dharma Univ., Indonesia, 2020 [Online]. Available:

https://repository.usd.ac.id/37608/2/164214120_f ull.pdf.

[22] A. Amirdabbaghian, "Translation and Tourism: A Cross-Cultural Communication and the Art of Translating Menus," Journal of Basic and Applied Scientific Research, vol. 4, no. 4, pp. 11-19, Mar 2014 [Online]. Available: http://eprints.um.edu.my/20250/1/JBASR,\%20A pril,\%2011-19-2014.pdf.

[23] A.S. Petrc, K.Mikinac, I. Edmonds, "Strategic Approaches to Menu Translation Analysis," ToSEE - Tourism in Southern and Eastern Europe, Vol. 5, pp. 689-703, Sep 2019 [Online]. Available: https://doi.org/10.20867/tosee.05.31.

[24] N. T. M. Tam, N. T. D. Hong, T. T. Long, "Khảo sát thực trạng sử dụng tiếng Anh trong các biển hướng dẫn du lịch tại một số điểm du lịch ở Miền Bắc Việt Nam," VNU Journal of Foreign Studies, vol. 33, no. 2, pp. 90-104, Mar 2017 [Online]. Available: $\quad$ https://doi.org/10.25073/25252445/vnufs.4144.

[25] N. T. N. Ngoc and L. K. Hoang, "Common Vietnamese-English translation errors in photo captions: A case study at the War Remnants Museum in Ho Chi Minh City, Vietnam," Translation Journal, vol. 21, no. 3, Jul 2018 [Online]. Available: https://translationjournal.net/July-2018/commonvietnamese-english-translation-errors-in-photocaptions-a-case-study-at-the-war-remnantsmuseum-in-ho-chi-minh-city-vietnam.html.

[26]D. Robinson, Becoming a translator: An introduction to the theory and practice of translation. London: Routledge, Dec 2019 [Online]. Available: https://doi.org/10.4324/9780429276606. 